\title{
Physics Abounds at Conference on Math and Art
}

\author{
Quasicrystals, the Markov-chain model, and topological surfaces were just
}

a few of the physics concepts on display at the 2021 Bridges conference.

By Katherine Wright

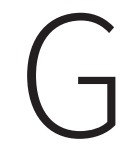
eorge Hart has attended all but one of the 24 Bridges conferences, which are dedicated to math-inspired art. A friend invited the engineer to the first meeting in 1998 and "it was so much fun," he says, that he has kept going back. Hart, who is also currently the president of the Bridges Organization, is not alone in his love of the meeting: "Most people who come to a Bridges conference keep coming back for the rest of their lives," he says. "We are like a big family."

The people who attend the Bridges conferences come from diverse backgrounds, but they all have one thing in common:

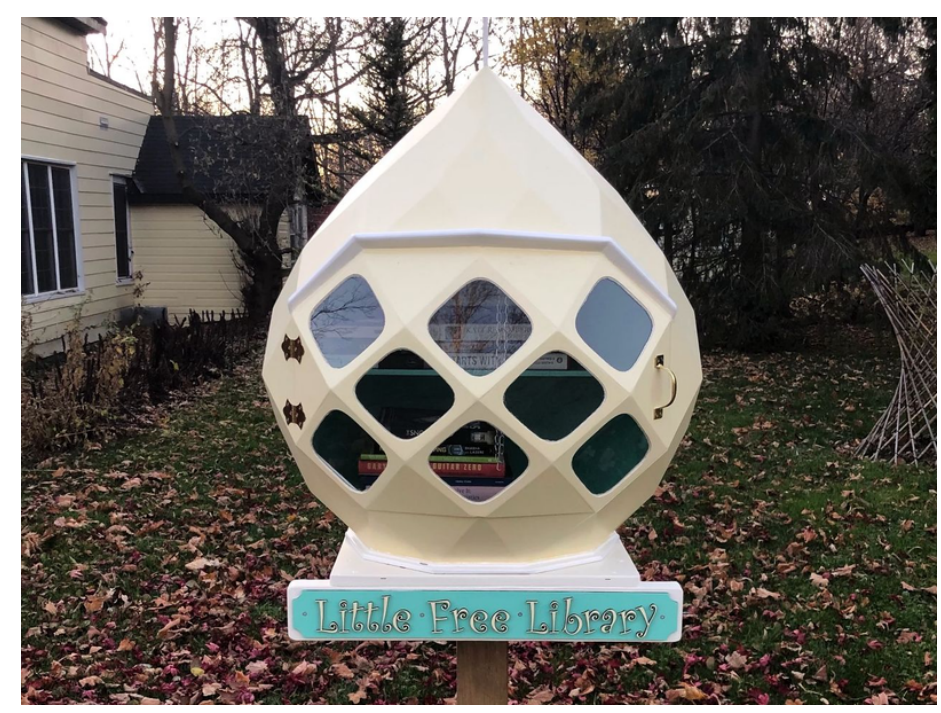

The engineer and sculptor George Hart shared his polar zonohedral-shaped structures, and the math behind them, at the 2021 Bridges conference.

Credit: E. Heathfield they love math and art. The lineup of presenters at this year's conference included an artist who makes jewelry using quasicrystal patterns, a math professor who uses Markov-chain equations to create tapestries, and a math teacher who creates sculptures as teaching aids. Mathematics was not only the inspiration of the art pieces on display, it was also a part of the construction, as many of the artists had to solve physics and engineering problems as they, for example, molded willow twigs into topological shapes, folded paper in curved lines, or created animals from orange peels.

Given the abundance of striking works and the interesting visualizations of math and physics that were on display, it seemed a shame to share just one. So here are a few of the art works and artists that caught Physics' attention.

\section{Markov-Controlled Tapestries}

The Markov-chain model is used to describe the dynamics of physical systems from the spread of a virus (see Viewpoint: The Uncertain Future in How a Virus Spreads) to the operation of elements of a quantum computer (see Viewpoint: Dissipative Stopwatches). Joshua Holden, a math professor at the Rose-Hulman Institute of Technology in Indiana, discussed how he uses the model's equations to design tapestry patterns, which he then fabricates using a technique known as tablet weaving.

Tablet weaving produces long thin strips of patterned material by passing threads through perforated cards that are incrementally rotated by small angles after each weaving sequence. The optimal series of rotations is one that keeps the cards close to their starting positions, which prevents unwanted 


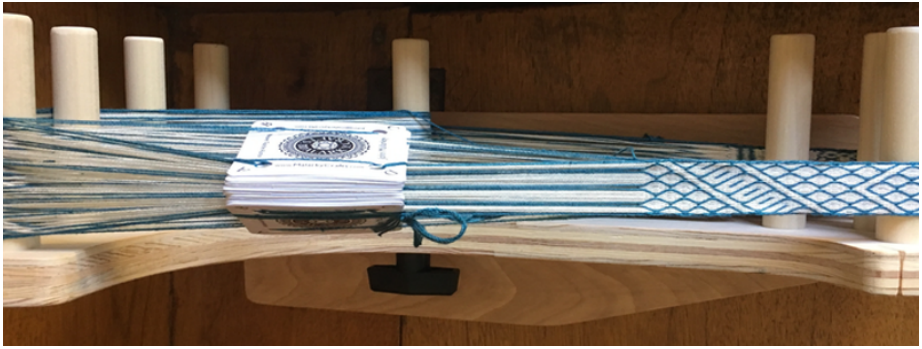

A photograph of Holden's tablet-weaving loom. Credit: J. Holden

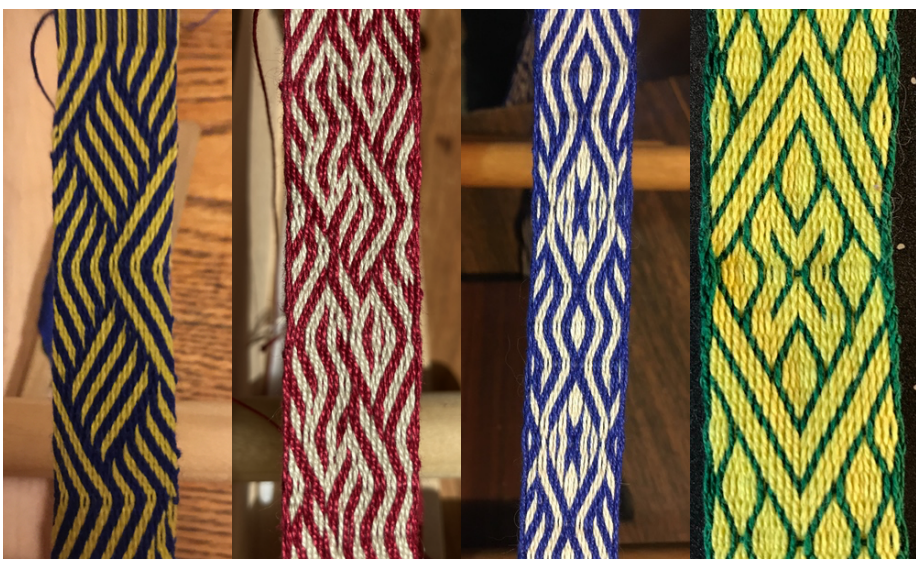

Examples of the different patterns Holden has created using the Markov-chain model.

Credit: J. Holden

twisting in the yet-to-be woven threads, Holden says. One model commonly used in math and physics to describe such a "mean-reverting" process is a version of the Markov-chain model known as the Ehrenfest model. This model describes the motion of a particle that is influenced by an elastic force that pulls the particle back toward its starting point. Holden showed that the model works well for pre-defining the card rotations needed to create patterns in his tapestries, which include Coptic diamonds and Egyptian-style diagonal weaves.

\section{Topological Willow}

Hedy Hempe is an artist first and a math-dabbler second. From the Netherlands, Hempe creates, among other things,

bigger-than-life-sized structures from willow twigs. In her most recent piece, which she presented at Bridges, Hempe combined weaving and braiding to produce a torus willow sculpture with a

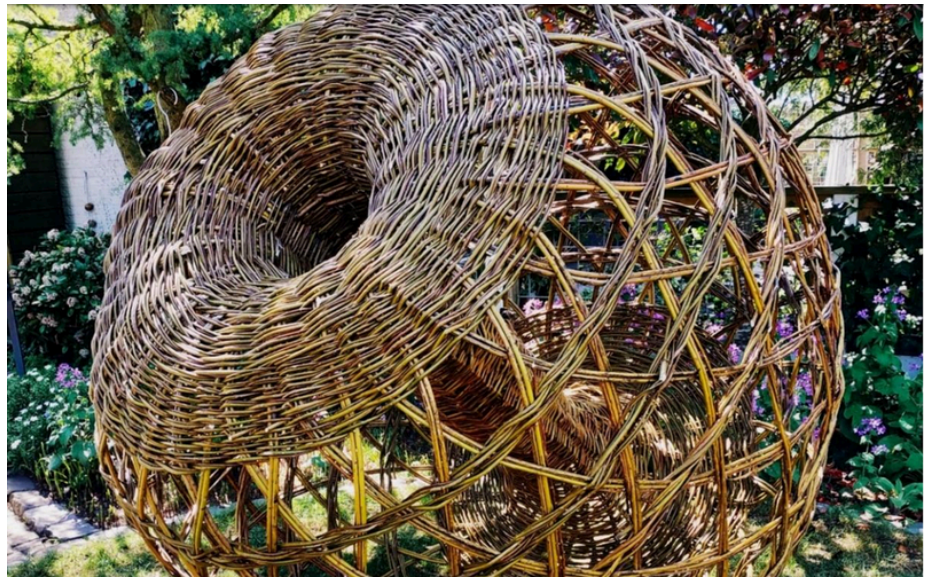

Hempe creates topological structures, including this torus, from willow twigs.

Credit: H. Hempe

central pattern that resembled the kagome lattice.

The kagome lattice is a hexagonal structure that appears in certain crystals, some of which exhibit exotic magnetic properties associated with so-called quantum spin liquids. Hempe says that she wasn't initially aware of the scientific aspects when she designed her sculpture, but she became interested in the mathematical models of the lattice once she started working on the piece. However, she notes that, while the mathematical intricacies of the kagome pattern are interesting, she felt no need to perfectly replicate them in her sculpture. "I'm not on Earth to solve the mysteries of nature through math, but to reveal the mysteries with my art," she says.

\section{Surprising Structures}

Like Hart, Bathsheba Grossman has been attending Bridges conferences since their inception. But, she says, she chose to miss some of the recent gatherings partly to work more privately and partly because the cost of attending was sometimes prohibitive. The virtual format of this year's conference, though, allowed her to present from the comfort of her home, which was "an irresistible opportunity to connect with old, and new, colleagues," she says. "It's a silver lining" to the pandemic-ridden world.

Grossman was one of the first mathematics-inspired artists to embrace 3D printing, a technology she still uses to create palm-sized sculptures of geometrical structures. These 


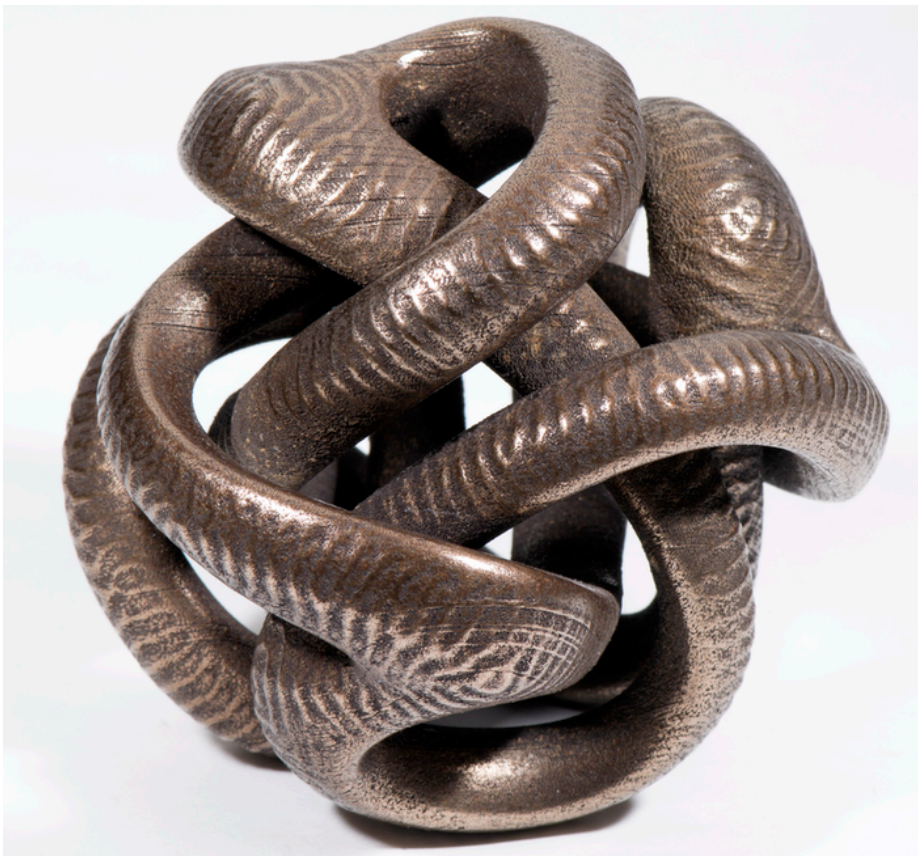

3D-printed steel sculpture designed using mathematical algorithms.

Credit: B. Grossman structures include Klein bottles (see Repackaging a Mathematically Odd Bottle) and triply periodic surfaces, whose designs come from mathematical algorithms that Grossman creates. But it was her recent venture into glass that took center stage in her talk.

The artist started working with glass when COVID-19 hit: she wanted something to do with her hands, but she also wanted to add spontaneity and surprise to her work. Her glass sculptures are inspired by her algorithm-based designs of reaction-diffusion patterns. But unlike her earlier 3D-printed sculptures that look identical to her simulations, the glass pieces come out differently every time, even with the same inputs. "You put the glass into the kiln, something happens, but you're not there for it, and then you take the sculpture out," she says. "It's very mysterious."

Katherine Wright is the Deputy Editor of Physics. 


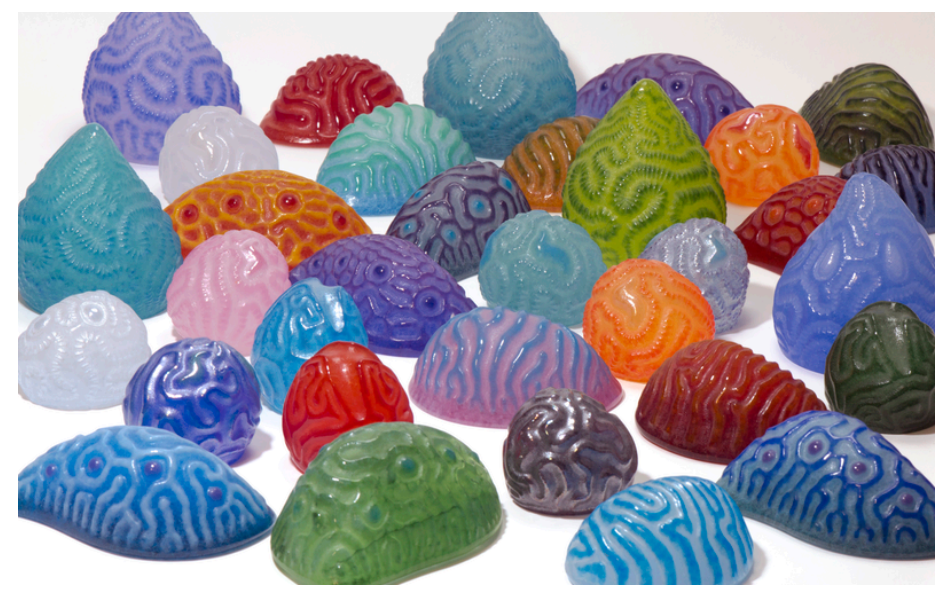

The wiggly surfaces of Grossman's recent glass sculpture series resemble the phase-separated patterns seen in physics in polymer and fluid mixtures, for example.

Credit: B. Grossman 